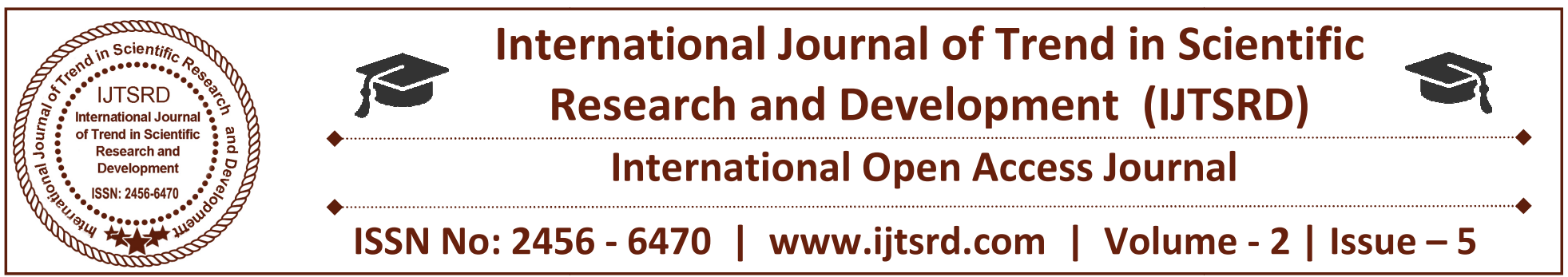

\title{
Technology in Solar Power Systems
}

\author{
Tayir Naqishbandi ${ }^{1}$, Shavet Sharma ${ }^{2}$ \\ ${ }^{1}$ M.Tech Scholar, ${ }^{2}$ Assistant Professor \\ Department of Electrical Engineering, Sri Sai College of Engineering \& Technology \\ Badhani, Pathankot, Punjab, India
}

\begin{abstract}
Solar power is one of the main sources of electricity used in our day by day life. Solar based energy resolves the shortage of electricity to great extent and covers most of the consumers belonging to backward category. Govt. of India also launched number of schemes in-collaboration with different banks to make consumers more and more aware regarding Solar Power and offers home based Solar Power Systems. In this paper the focus is on how to implement technologies to make solar power systems more and more efficient.
\end{abstract}

\section{KEYWORD: Sensor, IOT, PV panels.}

\section{INTRODUCTION}

Just like wind power, solar power is a virtually unlimited and inexhaustible resource (unlike power produced from expendable fossil fuels). As technologies improve and the materials used in PV panels become "greener," the carbon footprint of solar power becomes smaller and smaller and the technique becomes more accessible to the masses. Solar power is a form of energy harnessed from the power and heat of the sun's rays. It is renewable, and therefore a "green" source of energy. The most common way of harnessing energy from the sun is through photovoltaic (PV) panels - those large, mirror-like panels you've likely seen on rooftops, handheld solar devices, and even spacecraft's. These panels operate as conductors, taking in the sun's rays, heating up, and creating energy (and electricity). On a larger scale, solar thermal power plants also harness the power of the sun to create energy. These plants utilize the sun's heat to boil water and, in turn, power steam turbines. These plants can supply power to thousands of people. Today everyone is aware about the Solar
Power but now the demand is how to monitor theses Power Plants using latest and emerging technologies to make optimum power output. Implementing technology for monitoring Solar Plants helps to retrieve efficient power output.

\section{Remote Monitoring}

Remote Monitoring at the Solar Power Plants, keeping up the health of the Solar PV System is of paramount importance, and continuous monitoring is required. As most of the Solar PV Plants are installed in remote locations, the Operations \& Maintenance (O\&M) provider will need to use all ways and means to get firm information about the plant performance daily. The O\&M provider usually will have a limited knowledge of the local weather conditions and the effect of the terrain on plant performance. When the Generation goes down/dips, their engineers/monitoring personnel cannot step outside the control room always to know which part of the plant is under performing or if there are weather related changes within the plant in a large acreage setup. Therefore, to bridge the information gap and to get seamless updates about plant performance, Remote Monitoring systems are very essential. Remote monitoring is possible even from a central office of the client or the O\&M provider's Headquarters (HQ) in a different location, with proper authentication measures. The latter complements the efforts of the monitoring personnel at site and is more tweaked towards analysis of the data as received. Predictive analytics is the way forward for organizations which have a matured O\&M plant monitoring set up.

Irrespective of size of the plants, comprehensive 
monitoring is important for tracking yields at the plants minute by minute. The decision for the installation of a solar power plant means that it is not only choosing an eco-friendly technology but also a long term source of income for the investor. Therefore, to aid this goal the monitoring systems should run uninterrupted at all the times. Monitoring the generation /yields regularly provides vital piece of information in advance when the system performance is low or is likely to fail. Based on the measures, preventive maintenance can be carried out to enhance the performance and the health of the system or the maintenance schedules judiciously planned.

\section{The IOT Technology:}

The IOT is rapidly becoming a reality that surrounds us and intersects with many aspects of our lives. Pervasive connectivity and advances in ICT technologies have made possible the connection of more and more devices to the Internet. This is leading to a new wave of applications that have the potential to dramatically improve the way people live, learn, work, and entertain themselves. Sensors play a key role in connecting the physical world (temperature, $\mathrm{CO}_{2}$, light, noise, moisture) with the digital world of IOT. The IOT technology is very important like in solar power plants which need to be monitored for optimum power output. This helps retrieve efficient power output from power plants while monitoring for faulty solar panels, connections, and dust accumulated on panels lowering output and other such issues affecting solar performance.

\section{Sensor Technologies}

We live in an age of relentless and accelerating change, driven by demographic, social, and economic evolution. Each day, there are more of us consuming the finite natural resources of the planet. Our impact on the planet is increasing through urbanization, energy utilization, waste production, and so on, and this impact is not without consequences. Levels of pollution are increasing in our environment, with corresponding effects on our health and well-being. From smog clouds in cities and pollution of our drinking water to simply being denied sufficient peace to sleep soundly at night, human activity has enormous impact on us and on our planet. Major changes in the way we work and live during the last century mean we are also living much more sedentary lifestyles. This has resulted in growing public health issues, such as obesity, arteriosclerosis, cancer, chronic liver disease, and other lifestyle diseases.
Increased life expectancy places greater pressures on our healthcare systems as the world's population continues to grow older. Governments are being forced to cut programs such as home healthcare assistance to reduce burgeoning costs. The current model simply does not scale into the future.

Sensors play an integral role in numerous modern industrial applications, including food processing and everyday monitoring of activities such as electricity, transport, air quality, medical therapeutics, and many more. While sensors have been with us for more than a century, modern sensors with integrated information and communications technology (ICT) capabilitiessmart sensors - have been around for little more than three decades. Remarkable progress has been made in computational capabilities, storage, energy management, and a variety of form factors, connectivity options, and software development environments. These advances have occurred in parallel to a significant evolution in sensing capabilities. We have witnessed the emergence of biosensors that are now found in a variety of consumer products, such as tests for pregnancy, cholesterol, allergies, and fertility. We can deploy different types of sensors in our electrical domain also to introduce smartness like ATmega32 with IOT Gecko.

\section{Conclusion:}

In this paper I have briefly described technical aspects for solar power systems. The IOT is the very special technology used to control hardware devices using internet technology. The implementation of IOT and sensors are very useful for such power systems. Using latest and emerging technologies we can make the solar power plants more reliable and efficient like remote monitoring of solar power plants for optimum output.

\section{REFERENCES:}

1. B. Shrihariprasath, Vimalathithan. Rathinasabapathy,"A smart IoT system for monitoring solar PV power conditioning unit"2016, World Conference on Futuristic Trends in Research and Innovation for Social Welfare (Start up Conclave).

2. Charithperera chi haroldliu, srimaljayawardena, "the emerging internet of thing market place from an industrial perspective: a survey" december 2015, IEEE transactions on emerging topic in computing. 
3. yejihua, wang wen, "research and design of solar photovoltaic power generation monitoring system based ontiny os", august2014, 9th international conference on computer science education.

4. Chagitha Ranhotigamage and Subhas Chandra Mukhopadhyay, "Field Trail and Performance Monitoring Of Distributed Solar Panels Using Low Cost Wireless Wireless Sensor Networks", October 2010, IEEE Sensor journal.

5. Sol Moon, Sung-Guk Yoon and Joung-Hu Park, "A New Low Cost Centralized MPPT Controller System For Multiply Distributed Photovoltaic Power Conditioning Module", November 2015, IEEE Transactions on Smart Grid.

6. Ali Hosein Arianfar, M. Hosein Mehraban Jahromi, Mohsen Mosalanejad and Bahram Dehghan "Design And Modelling Remote Monitoring System For A Solar Power Plant", 2009,Second International Conference on Computer and Electrical Engineering.

7. Ravi Tejwani, Girish Kumar, Chetan Solanki, "Remote Monitoring System For Solar Photovoltaic Systems In Rural Application Using Gsm Voice Channel" 2013,ISES Solar World Congress.

8. Martín E. Andreoni Lopez, Francisco J. Galdeano Mantinan, and Marcelo G. Molina "Implementation of Wireless Remote Monitoring and Control of Solar Photovoltaic (PV) System" 2012 IEEE Conference Publications.

9. J. H. So, B. G. Yu, H. M. Hwang, G. J Yu and I. Y. Choi "Performance Monitoring and Analysis of Middle Scale Grid Connected PV System', october 2007, 7th International conference on power electronics.

10. Ms. N. S. Deshmukh, Prof. D. L. Bhuyar, Prof. A. T. Jadhav "Review on IOT Based Smart Solar Photovoltaic Plant Remote Monitoring and Control Unit" 2018, International Journal of Advance Scientific Research and Engineering Trends, Volume 3 || Issue 3

11. Mamatha C. R, Abhishek Kumar Singh, Shazia Amreen "Solar Powered Green House Monitoring and Controlling using AWS Cloud by Android Application" 2017, International Research Journal of Computer Science (IRJCS), Issue 05, Volume 4.

12. Shrihariprasath Basuvaiyan, Vimalathithan Rathinasabapathy "IOT based Solar Photo Voltaic Monitoring System" 2017, https://www.researchgate.net/publication/3213078 47.
13. R. Vignesh, Dr. A. Samydurai "Automatic Monitoring and Lifetime Detection of Solar Panels Using Internet of Things" 2017, International Journal of Innovative Research in Computer and Communication Engineering, Vol. 5 , Issue 4.

14. Urvashi Narwal, Nikita "Home Automation by Integrating Solar Based System With in Internet of Thing" 2016, International Journal of Scientific Research and Education, Volume $\|4\|$ Issue $\| 08$.

15. Putta Sindhuja, M. S. Balamurugan "Smart Power Monitoring and Control System through Internet of things using Cloud Data Storage" 2015, Indian Journal of Science and Technology, Vol 8(19), DOI:10.17485/ijst/2015/v8i19/76698.

16. Jiju K. et. al., 2014. "Development of Android based on-line monitoring and control system for Renewable Energy Sources." Computer, Communications, and Control Technology (I4CT), International Conference on. IEEE, 2014.

17. Yoshihiro G. et. al., 2007. "Integrated management and remote monitoring system for telecommunications power plants with fully DCpowered center equipment." INTELEC 07-29th International Telecommunications Energy Conference. IEEE, 2007.

18. Alexander S. and Galkin I., 2013. "Case study on using non-intrusive load monitoring system with renewable energy sources in intelligent grid applications." International Conference Workshop Compatibility And Power Electronics.

19. Mayamiko N., Zennaro M. and Bagula A., 2011. "SM 2: Solar monitoring system in Malawi." Kaleidoscope: The Fully Networked Human?Innovations for Future Networks and Services (K2011), Proceedings of ITU. IEEE, 2011.

20. Li W. and Liu K.-H., 2007. "Implementation of a web-based real-time monitoring and control system for a hybrid wind-PV-battery renewable energy system." Intelligent Systems Applications to Power Systems, ISAP 2007. International Conference on. IEEE, 2007.

21. Big data (Dec 2016) Retrieved from http://bigdatamadesimple.com Internet of things (Nov 2016) .Retrieved from http://cerasis.com/2015/10/20/10-things-toknowabout-the-internet-of-things "Internet of Things Global Standards Initiative". ITU. Retrieved 26 June 2015. "Internet of Things: Science Fiction or Business Fact?" (PDF). Harvard Business Review. November 2014. Retrieved 23 October 2016. 